\title{
INFLUÊNCIA DO FORNECIMENTO PROLONGADO DE COLOSTRO SOBRE A FLUTUAÇÃO DE PROTEÍNAS SÉRICAS EM BEZERROS COM DIFERENTES NIVVIS DE IMUNIDADE PASSIVA SÉRICA ${ }^{1}$
}

\author{
R.S. BARACAT²; R. MACHADO NETO ${ }^{2}$; C. DANIELE'; R. BESSI'; I.U. PACKER ${ }^{3}$ \\ ${ }^{2}$ Departamento de Zoologia-ESALQ/USP, C.P. 9 - CEP: 13418-900 - Piracicaba, SP. \\ 'Departamento de Zootecnia-ESALQ/USP, C.P. 9 - CEP: 13418-900, Piracicaba, SP.
}

\begin{abstract}
RESUMO: 0 presente trabalho teve como objetivo avaliar o comportamento das proteínas séricas de 32 bezerros recém-nascidos submetidos a diferentes programas de aleitamento. Foram utilizados animais com duas diferentes condicōes de imumidade passiva adquirida, alta e baixa, divididos em dois grupos, com e sem fornecimento prolongado de colostm. Os tratamentos foram os seguintes: T1 - alto/leite; T2 -baixo/leite; T3 - alto/colostro; T4 - baixo/ colostm. Foram avaliados os parâmetros séricos de protefna total (PT), albumina e imunoglobulina G (IgG). 0 grupo alto (T1 e T3) apresentou uma concentraçāo mélia superior de protef́na total $(p=0,0033)$ e imumoglobulina $(p=0,0001)$ séricas comparadas com os valores encontrados para o grupo baixo (T2 e T4). Protefna total e albumina apresentaram concentraç̄es médias superiores $(p=0,0001$ e $p=0,059)$ no grupo colostro (T3 e T4) comparado com o grupo leite (T1 e T2). Os valores mínimos médios para PT e IgG foram superiores $(p=0,082$ e $p=0,0001)$ no grupo alto comparado com o grupo baixo. A data de ocorrencia do valor médio mínimo no grupo alto para $P T$ foi 40 dias, valor superior $(p=0,0012)$ aos 20 dias encontrado para o grupo baixo. 0 mesmo ocorreu para IgG $(p=0,060)$, tendo sido obtido 50 e 40 dias, respectivamente, para os grupos alto e baixo. Os animais que receberam colostro (T3 e T4) apresentaram, apenas para $P T$, valor superior $(\mathrm{p}=0,0002)$ para o parâmetro menor valor médio, que ocorreu aos 30 dias de idade. A data de ocorrência do valor médio mínimo para IgG não diferiu entre os animais que receberam colostro e leite ( 40 dias). $O$ fornecimento prolongado de colostro na dieta pode favorecer o processo de síntese de proténas séricas em bezerros recém-nascidos.
\end{abstract}

Descritores: colostro, protefnas séricas, imunidade passiva, hezerro

\section{INFLUENCE OF EXTENDED COLOSTRUM FEEDING ON PROTEIN FLUCTUATION OF NEW BORN CALVES WITH DIFFERENT ACQUIRED PASSIVE IMMUNTTY.}

\begin{abstract}
The objective of this study was to evaluate the protein fluctuation of 32 Holstein newborn calves under different millk feeding programs. Animals with high and low condition of acquired passive immunity, were splited in two groups, with and without extended colostrum feeding. The treatments were: T1 - high/milk; T2 - low/milk; T3 high/colostrum; T4 - low/colostrum. Total protein (TP), albumin and imunoglobulin G (IgG) present in the serum of the calves were evaluated. Calves of $\mathrm{T} 1$ and $\mathrm{T} 3$ showed higher concentration of TP and IgG as compared to T2 and T4. TP and albumin concentration were higher $(P=0,0001 \mathrm{e}=0,059)$ in $\mathrm{T} 3$ and $\mathrm{T} 4$ in relation to animals in $\mathrm{T} 1$ and T2. The lowest concentration of $P T$ and $\operatorname{IgG}$ were higher $(p=0,082$ e $p=0,0001)$ in $T 1$ and $T 3$ as compared to $T 2$ and T4. The date when the lowest concentrations of TP ocurred in T1 and T3, 40 days, was superior $(p=0,0012)$ to 20 days found in T2 and T4. The same ocurred to IgG ( $(p=0,060)$ with dates of 50 and 40 days for high (T1 and T3) and low (T2 and T4) groups respectively. Animals that received colostrum (T3 and T4) showed, only for TP, higher $(p=0,0002)$ concentrations in relation to the minimum concentration, which was registred at the age of 30 days. The date when the lowest concentration of IgG occurred was not different between animals that received colostrum and mill (40 days). According to the results it is suggested that colostrum in the diet has a positive effect in the serum protein synthesis, which in addition to immunoglobulins play an important role in the serum protein fuctuation of the newborm calves.
\end{abstract}

Key Words: colostrum, serum proteins, passive immunity, calf

\footnotetext{
${ }^{1}$ Parte da dissertação de mestrado do primeiro autor apresentada à ESALQ/USP, parcialmente financiada pelo CNPq.
} 


\section{INTRODUÇÃO}

Em função da ausência de transferência de anticorpos maternos via placenta, bezerros nascem praticamente sem imunoglobulinas passivas na corrente sanguínea. Para estes animais o colostro se constitui no veículo de transporte dos anticorpos da mãe para o filho. São inúmeros os fatores que a fetam este mecanismo. Nesta fase inicial da vida do bezerro, os níveis das proteínas séricas apresentam marcantes variações, sendo em grande parte consequência da aquisição das imunoglobulinas do colostro (BRAMBELL, 1958; MORRIS, 1968; JEFFCOTT, 1972; PORTER, 1979).

Após as primeiras 24 horas de vida pouca ou nenhuma absorção de imunoglobulina ocorre. As células do intestino, onde se dá este mecanismo de absorção, perdem a capacidade de transferir as imunoglobulinas da luz intestinal para as vias sistêmicas. Vários são os fatores que a fetam o processo de absorção de anticorpos do colostro pelo recém-nascido (EDWARDS et al., 1982; KRUSE, 1983; DONOVAN et al., 1986; MICHANEK et al., 1989; VENTORP \& MICHANEK, 1992).

Além do fornecimento de colostro durante as primeiras 24 horas de vida, o que permite que se atinja níveis séricos adequados, vários autores têm demonstrado que $o$ fornecimento de colostro suplementar, mesmo após o período absortivo, tem um papel positivo na proteção contra patógenos entéricos. A presença das imunoglobulinas no lume intestinal de modo continuado envolvendo os enterócitos reduz 0 ataque de vírus e bactérias (SNODGRASS \& WELLS, 1978; SAIF et al., 1983; NOCEK et al., 1984; CASTRUCCI et al., 1989; MACHADO NETO et al., 1989; TSUNEMITSU et al., 1989; DANIELE et al., 1994a).

Este trabalho teve como objetivo estudar o efeito do fornecimento prolongado de colostro sobre o comportamento das proteínas séricas de bezerros recém-nascidos com diferentes níveis de imunidade passiva sérica inicial.

\section{MATERIAL E MÉTODOS}

O trabalho de foi conduzido na Fazenda Santa Rita - Agrindus S.A., município de Descalvado, Estado de São Paulo, tendo sido utilizados 32 bezerros recém-nascidos da raça Holandesa preta e branca.
Entre 24 e 48 horas de vida os animais tinham o sangue coletado para estimativa da aquisição de anticorpos passivos, através do método descrito por McEVAN et al. (1970). Por este teste, utilizado nesta primeira análise por requisitar pouco tempo para sua execução, a concentração de anticorpos séricos é expressa em unidades de ZST (1 unidade ZST corresponde a $0,75 \mathrm{mg} / \mathrm{ml}$ de imunoglobulina sérica). Com base nestes resultados os bezerros foram separados em dois grupos, nos quais os animais que apresentaram quantidades de imunoglobulinas acima de 27 unidades ZST foram designados ao grupo alto e com quantidades iguais ou abaixo deste valor, ao grupo baixo. Dentro destes dois grupos, os animais foram ainda separados, ao acaso, por ordem sorteada previamente de acordo com a dieta recebida (leite ou colostro). Os tratamentos ficaram assim determinados:

$\mathrm{T} 1$ = alto/leite: grupo alto que recebeu $4 \mathrm{I}$ de leite, em duas refeições diárias, dos 3 dias de idade até a desmama.

T2 = baixo/leite: grupo baixo que recebeu 41 de leite, em duas refeições diárias, dos 3 dias de idade até a desmama.

T3 = alto/colostro: grupo alto que recebeu 1,41 de leite $+0,61$ de colostro pela manhã e igual quantidade à tarde, dos 3 aos 30 dias de idade.

T4 = baixo/colostro: grupo baixo que recebeu 1,41 de leite $+0,61$ de colostro pela manhã e igual quantidade à tarde, dos 3 aos 30 dias de idade.

$O$ leite fornecido aos animais era integral, proveniente de ordenhas diárias. $O$ colostro de primeira e segunda ordenhas dos animais em lactação foi armazenado em "pools" e fornecido aos animais do T3 e T4. A quantidade média recebida de imunoglobulinas através dos "pools", quantificada pelo emprego do colostrômetro (FLEENOR \& STOTT 1980), foi de $93,08 \pm 28,432 \mathrm{~g} / \mathrm{dia}$.

A amostragem de sangue foi feita aos 3 , $5,10,15,17,20,22,25,30,40,50$ e 60 dias de idade. $O$ sangue foi centrifugado $e o$ soro resultante foi resfriado a $-20^{\circ} \mathrm{C}$.

Para análise da proteína total sérica foi utilizado o método de biureto (REINHOLD, 1953), sendo o resultado da reação final lido em espectrofotômetro com comprimento de onda ajustado em $545 \mathrm{~nm}$.

A albumina sérica foi separada através de eletroforese em fita de acetato de celulose, utilizando-se uma diferença de potencial de 200 volts e tampão barbital sódico. Após a separação, a fração 
albumina foi revelada com corante Ponceau-S por 10 minutos. A quantificação foi feita com a leitura em densitômetro da fita revelada.

A quantificação de imunoglobulina $\mathbf{G}$ (IgG) sérica dos bezerros foi feita pelo método de imunodifusão radial (MANCINI et al. 1965), tendo sido usado IgG e anti-IgG da Sigma Chemical Company-USA. Além da curva padrão, todas as placas com as amostras continham duas concentrações padrão, para controle da variação entre placas. As duplicatas com variações acima de $5 \%$ foram repetidas.

O delineamento experimental empregado foi de parcelas subdivididas em um esquema fatorial, utilizando-se o programa SAS/STAT para análise estatística dos dados.

\section{RESULTADOS E DISCUSSÃO}

Nas TABelas 1,2 e 3 estão apresentadas respectivamente as concentrações séricas médias de proteína total (PT), albumina e imunoglobulina G (IgG).

Pela análise de variância verificou-se que a interação entre dieta (leite ou colostro) e condição de imunidade passiva sérica inicial (alta ou baixa) não foi significativa.

Através da análise dos valores de PT foi constatada uma diferença significativa entre os animais dos grupos alto (leite e colostro) e baixo (leite e colostro) $(p=0,0033)$. Os valores médios foram 7,13 $\pm 0,70 \mathrm{~g} / 100 \mathrm{ml}$ para o grupo alto e $6,48 \pm 0,70 \mathrm{~g} / 100 \mathrm{ml}$ para o grupo baixo. 0 mesmo comportamento foi verificado para IgG $(p=0,0001)$ com valores de $33,42 \pm 7,0 \mathrm{mg} / \mathrm{ml}$ para o grupo alto e $21,5 \pm 6,1 \mathrm{mg} / \mathrm{ml}$ para o grupo baixo.

Para o parâmetro albumina sérica não foi constatada diferença significativa entre os grupos alto e baixo.

Através de análises de correlação entre PT e IgG séricas, utilizando valores do terceiro dia de idade, verificou-se um coeficiente de correlação positivo $(p<0,01)$ entre os parâmetros $(r=0,76)$. Resultados semelhantes, com coeficientes de correlação em torno de 0,80 , foram obtidos por NOCEK et al. (1984) e MACHADO NETO \& PACKER (1986).

Entre os valores obtidos para PT, nos tratamentos que receberam colostro (alto e baixo) e leite (alto e baixo) houve diferença significativa (p $=0,0001)$, tendo sido obtido os valores 7,27 \pm

TABELA 1. Concentração média de proteína total sérica $(\mathrm{g} / 100 \mathrm{ml})$ para os quatro tratamentos.

\begin{tabular}{|c|c|c|c|c|}
\hline \multirow{2}{*}{ Idade } & Trat. 1 & Trat. 2 & Trat. 3 & Trat. 4 \\
\hline & Média DP & Média DP & Média DP & Média DP \\
\hline 3 & $8,32 \pm 0,79$ & $6,38 \pm 0,91$ & $8,92 \pm 0,90$ & $6,85 \pm 0,82$ \\
\hline 5 & $7,77 \pm 0,87$ & $6,28 \pm 0,88$ & $8,61 \pm 0,96$ & $7,04 \pm 0,82$ \\
\hline 10 & $7,43 \pm 1,40$ & $6,10 \pm 0,68$ & $7,75+0,39$ & $6,95 \pm 0,69$ \\
\hline 15 & $6,58 \pm 0,80$ & $5,71 \pm 0,70$ & $7,48 \pm 0,85$ & $6,73 \pm 0,48$ \\
\hline 17 & $6,83 \pm 1,55$ & $5,85 \pm 0,76$ & $7,29 \pm 0,69$ & $6,93 \pm 0,45$ \\
\hline 20 & $6,57 \pm 0,76$ & $5,95 \pm 0,74$ & $7,38 \pm 0,48$ & $6,99 \pm 0,39$ \\
\hline 22 & $6,31 \pm 0,59$ & $5,91 \pm 0,97$ & $7,45 \pm 0,34$ & $6,86 \pm 0,34$ \\
\hline 25 & $6,18 \pm 0,40$ & $5,81 \pm 0,83$ & $7,28 \pm 0,39$ & $6,96 \pm 0,58$ \\
\hline 30 & $6,09 \pm 0,47$ & $5,59 \pm 0,70$ & $7,38 \pm 0,39$ & $7,12 \pm 0,43$ \\
\hline 40 & $5,97 \pm 0,97$ & $5,81 \pm 0,80$ & $6,82 \pm 0,49$ & $6,79 \pm 0,26$ \\
\hline 50 & $5,88 \pm 0,62$ & $5,93 \pm 0,87$ & $7,10 \pm 0,55$ & $7,33 \pm 1,05$ \\
\hline 60 & $6,37 \pm 0,50$ & $6,05 \pm 0,82$ & $6,89 \pm 0,59$ & $7,45 \pm 0,88$ \\
\hline Média & $6,69 \pm 0,81$ & $5,95 \pm 0,80$ & $7,53 \pm 0,59$ & $7,00 \pm 0,60$ \\
\hline
\end{tabular}

Trat. 1: grupo alto/leite

Trat. 2: grupo baixo/leite

Trat. 3: grupo alto/colostro

Trat. 4: grupo baixo/colostro

DP: desvio padrão. 
$0,60 \mathrm{~g} / 100 \mathrm{ml}$ para o grupu colostro e $6,33 \pm 0,80$ g/100 ml para o grupo leite. 0 mesmo comportamento também foi observado $(p=0,059)$ para o parametro albumina. Os valores médios para os animais que receberam colostro e leite foram respectivamente $3,23 \pm 0,58$ e 3,03 $\pm 0,60 \mathrm{~g} / 100$ ml. Nesta mesma situação, para IgG, não foi observada nenhuma diferença significativa. Resultados semelhantes foram verificados nos estudos desenvolvidos por MACHADO NETO et al. (1986) e DANIELE et al. (1994b).

De acordo com estes resultados sugerese um efeito positivo da presença de colostro na dieta sobre a produção de proteínas séricas, incluindo a fração albumina, sem interferir na flutuação da fração IgG.

Para o valor médio mínimo foj encontrada uma diferença significativa para idade $e$ concentração, quando foram considerados os valores de PT agrupados em alto e baixo. Houve diferença significativa $(p=0,0822)$ entre o menor valor médio de PT sérica encontrado nos animais do grupo alto $(6,09 \pm 0,65 \mathrm{~g} / 100 \mathrm{ml})$ e baixo $(5,74 \pm 0,72 \mathrm{~g} / 100$ $\mathrm{ml}$ ) e nas idades de ocorrência destes valores ( $p=$ 0,0012), sendo aos 40 e aos 20 dias, respectivamente.
Para IgG ocorreu também diferença significativa entre os menores valores para os animais dos grupos alto e baixo $(p=0,0001)$ e nas idades de ocorréncia destes valores $(p=0,060)$. As concentraçōes foram $22,54 \pm 4,0 \mathrm{mg} / \mathrm{ml}$ aos 50 dias e $15,19 \pm 4,7 \mathrm{mg} / \mathrm{ml}$ aos 40 dias, respectivamente para os grupos alto e baixo.

Entre os animais que receberam colostro e leite, a diferença do menor valor médio de PT sérica também foi significativa $(p=0,0002)$, mesmo não sendo verificado para as idades de ocorréncia. Assim os menores valores médios, registrados aos 30 dias de idade, foram 6,32 $\pm 0,49$ $\mathrm{g} / 100 \mathrm{ml} \mathrm{e} 5,50 \pm 0,63 \mathrm{~g} / 100 \mathrm{ml}$, respectivamente.

Entre os valores mínimos médios de IgG para os animais que receberam colostro ou leite na $\operatorname{dieta}(18,88 \pm 5,26 \mathrm{mg} / \mathrm{ml}$ e $18,76 \pm 6,24 \mathrm{mg} / \mathrm{ml})$, a diferença não foi significativa, o que também não se verificou para idade de ocorrência ( 40 dias).

$O$ ponto de concentração mínima média para PT reflete em grande parte a transição de uma fase de catabolismo para anabolismo da fração IgG, na qual estas passam de uma origem exógena para endógena (LOGAN et al, 1974; RIBEIRO et al., 1983; MACHADO NETO \& PACKER, 1986).

TABELA 2. Concentração média de albumina sérica $(\mathrm{g} / 100 \mathrm{ml})$ para os quatro tratamentos.

\begin{tabular}{|c|c|c|c|c|}
\hline \multirow{2}{*}{ Idade } & Trat. 1 & Trat. 2 & Trat. 3 & Trat. 4 \\
\hline & Média DP & Média DP & Média DP & Média DP \\
\hline 3 & $2,86 \pm 0,34$ & $2,83 \pm 0,57$ & $3,00 \pm 0,24$ & $3,09 \pm 0,45$ \\
\hline 5 & $2,72 \pm 0,85$ & $2,80 \pm 0,59$ & $2,82 \pm 0,45$ & $3,20 \pm 0,82$ \\
\hline 10 & $2,94 \pm 0,70$ & $2,83 \pm 0,55$ & $3,01 \pm 0,34$ & $2,76 \pm 1,02$ \\
\hline 15 & $2,96 \pm 0,67$ & $2,68 \pm 0,45$ & $3,01 \pm 0,55$ & $3,17 \pm 0,58$ \\
\hline 17 & $2,96 \pm 0,43$ & $2,97 \pm 0,50$ & $3,00 \pm 0,35$ & $2,79 \pm 1,10$ \\
\hline 20 & $2,89 \pm 0,52$ & $3,42 \pm 0,81$ & $3,23 \pm 0,68$ & $3,50 \pm 0,47$ \\
\hline 22 & $2,84 \pm 0,43$ & $3,29 \pm 0,63$ & $3,11 \pm 0,59$ & $3,88 \pm 0,77$ \\
\hline 25 & $3,04 \pm 0,51$ & $3,24 \pm 0,59$ & $3,41 \pm 0,38$ & $3,30 \pm 0,46$ \\
\hline 30 & $2,92 \pm 0,50$ & $3,07 \pm 0,71$ & $3,78 \pm 0,70$ & $3,78 \pm 0,61$ \\
\hline 40 & $3,19 \pm 0,59$ & $3,06 \pm 1,04$ & $3,30 \pm 0,34$ & $3,63 \pm 0,74$ \\
\hline 50 & $3,17 \pm 0,44$ & $3,26 \pm 0,91$ & $3,31 \pm 0,53$ & $3,34 \pm 0,66$ \\
\hline 60 & $3,24 \pm 0,56$ & $3,34 \pm 0,51$ & $3,37 \pm 0,73$ & $3,19 \pm 0,56$ \\
\hline Média & $2,98 \pm 0,55$ & $3,06 \pm 0,65$ & $3,20 \pm 0,46$ & $3,30 \pm 0,69$ \\
\hline
\end{tabular}

Trat. 1: grupo alto/leite

Trat. 2: grupo baixo/leite

Trat. 3: grupo alto/colostro

Trat. 4: grupo baixo/colostro

DP: desvio padrão. 
TABELA 3. Concentração média de imunoglobulina sérica (mg/ml) para os quatro tratamentos.

\begin{tabular}{ccccc}
\hline Idade & Trat. 1 & Trat. 2 & Trat. 3 & Trat. 4 \\
& Média DP & Média DP & Média DP & Média DP \\
\hline 3 & $45,66 \pm 5,37$ & $30,69 \pm 7,27$ & $48,12 \pm 0,12$ & $26,47 \pm 8,08$ \\
5 & $43,48 \pm 9,54$ & $30,03 \pm 7,21$ & $45,37 \pm 9,47$ & $26,50 \pm 8,57$ \\
10 & $42,21 \pm 11,20$ & $24,69 \pm 5,81$ & $42,28 \pm 8,66$ & $23,40 \pm 9,54$ \\
15 & $32,22 \pm 6,07$ & $19,97 \pm 3,99$ & $36,59 \pm 8,22$ & $20,76 \pm 7,02$ \\
17 & $32,87 \pm 5,72$ & $21,95 \pm 5,32$ & $38,57 \pm 9,43$ & $19,73 \pm 6,85$ \\
20 & $30,17 \pm 8,14$ & $21,39 \pm 4,21$ & $32,16 \pm 9,09$ & $18,98 \pm 6,97$ \\
22 & $32,37 \pm 7,90$ & $20,17 \pm 4,69$ & $30,62 \pm 9,36$ & $18,80 \pm 7,23$ \\
25 & $28,28 \pm 5,91$. & $19,26 \pm 4,21$ & $30,54 \pm 8,30$ & $16,98 \pm 6,52$ \\
30 & $29,52 \pm 5,41$ & $21,01 \pm 6,64$ & $27,37 \pm 6,94$ & $18,16 \pm 4,98$ \\
40 & $25,78 \pm 4,26$ & $18,10 \pm 7,09$ & $28,98 \pm 8,56$ & $18,24 \pm 5,73$ \\
50 & $24,64 \pm 5,49$ & $19,22 \pm 5,49$ & $25,92 \pm 6,73$ & $18,81 \pm 3,72$ \\
60 & $24,44 \pm 4,83$ & $22,27 \pm 4,46$ & $23,84 \pm 3,89$ & $20,34 \pm 4,57$ \\
\hline Média & $32,64 \pm 6,65$ & $22,40 \pm 5,53$ & $34,20 \pm 7,40$ & $20,60 \pm 6,65$ \\
\hline \hline
\end{tabular}

Trat. 1: grupo alto/leite

Trat. 2: grupo baixo/leite

Trat. 3: grupo alto/colostro

Trat. 4: grupo baixo/colostro

DP: desvio padrão.

Considerando-se o fato deste ponto ter ocorrido mais precocemente para PT do que para IgG, sugere-se que a flutuação de PT se deve a outras proteínas séricas, além de IgG.

\section{CONCLUSÃO}

Com base nos dados obtidos, o fornecimento prolongado de colostro tem efeito positivo na síntese de proteínas séricas.

\section{REFERÊNCIAS BIBLIOGRÁFICAS}

BRAMBELL, J.W.R. The passive immunity of young mammal. Biological Reviews, v.33, p.488-531, Nov. 1958.

CASTRUCCI, C.; FRIGERI, F.; FERRARI, M.; F. Further studies on passive imunization of newbom calves against rotaviral infection. Comparative Immunology, Microbiology and Infections Diseases, v.12, p.71-6, Out. 1989.

DONOVAN, G.A; BADINGA, L.; COLLIER, R.J.; WILCOX, C.S,; BRAUN, R.K; Factors influencing passive transfer in dairy calves. Journal of Dairy Science, v.69, p.754-9, Mar. 1986.
DANIELE, C.; MACHADO NETO, R.; BARACAT, R.S.; BESSI, R.; PACKER, I.U. Efeito de diferentes manejo no fornecimento prolongado de colostro sobre o comportamento imunológico e desempenho de bezerros leiteiros recém-nascidos. Revista da Sociedade Brasileira de Zootecnia, v.23, p.211-22, Mar./Abr. $1994 a$.

DANIELE, C.; MACHADO NETO, R.; BARACAT, R.S.; BESSI, R.; PACKER, I.U. Efeito de diferentes manejos de fornecimento prolongado de colostro sobre os níveis de proteína e albumina séricas e desempenho de bezerras recém-nascidas. Scientia Agricola, v.51, p.381-8, $1994 b$.

EDWARDS, S.A.; BROOM, D.M.; COLLIS, S.C. Factores affecting levels of passive immunity in dairy calves. British Veterinary Journal, v.138, p.233-40, Mai/Jun 1982.

FLEENOR, W.A.; STOTT, G.H. Hydrometer test for estimation of immunoglobulim concentration in bovine colostrum. Journal of Dairy Science, v.63, p.973-7, Jun 1980.

JEFFCOTT, L.B. Passive immunity and its transfer with special reference to the horse. Biological Reviews, $v$. 47, p. 439-64, Nov. 1972. 
KRUSE, P.E. The importance of colostal immunoglobulin and their absorption from the intestine of the newborn animals. Annales de Recherches Veterinaries, v.14, p.349-53, 1983.

LOGAN, E.F.; MCMURRAY, C.H.; O'NEIL, D.G.; McPARLAND, P.J.; McRORY, F.J. Absorption of colostral immunoglobulins by the neonatal calf. British Veterinary Journal, v. 134, p. 258-62, Mai/Jun 1978.

MACHADO NETO, R.; PACKER, I.U. Flutuação de imunoglobulina sérica em bezerros da raça holandesa submetidos a diferentes regimes de aleitamento. Revista da Sociedade Brasileirn de Zootecnia, v.15, p.43947, 1986.

MACHADO NETO, R.; PACKER, I.U.; SUSIN, I.; NOLASCO, A.M. Proteína total sérica em bezerros da raça Holandesa submetidos a diferentes regimes de aleitamento. Ansis da Escola Superior de Agricultara "Luiz de Queiroz", v.43, p.265-84, 1986.

MACHADO NETO, R.; PACKER, I.U.; SUSIN, I. Concentração de imunoglobulina sérica, peso corporal e diarréia, em bezerros da raça holandesa alcitados com diferentes dielas. Turrialba, v.39, p.51-5, jan./ mar. 1989.

MANCINI, G.; CARBONARA, A.O.; HEREMANS, J.F. Immunochemical quantitation of antigenous by single radial immunodiffusion. Immunochemistry, v.2, p.235-54, Fev. 1965.

MCEVAN, A.D.; FISHER, E.W.; SELMAN, I.E.; PENHALE, W.J. A turbidity test for the estimation of immunoglobulin levels in neonatal calf serum. Clinica Chimica Acta, v.27, p.155-63, 1970.

MICHANEK, P.; VENTORP, M.; WESTROM, B. Intestinal transmission of colostral antibodies in newborn dairy calves - initiation of closure by feeding colostrum. Swedish Joumsl of Agricultural Research, v.19, p.125-7, Set. 1989.

MORRIS, I.G. Gammaglobuline absorption in the newbom. In: CODE, C.F. ed. Hand book of plysiology alimentary camal. Baltimore: American Physiological Society, 1968. cap.3, p.1491-512.
NOCEK, J.E.; BRAUND, D.G.; WARNER, R.G. Influence of neonatal colostrum administration, immunoglobulin, and continued feeding of colostrum on calf gain, health, and serum protein. Joumel of Driry Science, v.67, p.319-33, Fev. 1984.

PORTER, P. Structural and functional characteristics of immunoglobulins of the common domestic species. Advances in Veterinary Science and Comparative Medicine, v.23, p.1-21, Mar. 1979.

RENHOLD, J.G. Total protein, albumin and globulin. In: REINER, M., ed. Standard methods of clinical Chemistry. New York: Academic Press, 1953. v.1, p.188.

RIBEIRO, M.F.B.; BELEM, P.A.D.; PARARROYO, J.H.; de FARIA, J.E. de. Hipogamaglobulinemia em bezerros. Arquivo Brasileiro de Medicina Veterinária e Zootecnia, v.35, p.537-46, Ago. 1983.

SAIF, L.J.; REDMAN, D.R.; SMITH, K.L.; THEIL, K.W. Pasaive immunity to bovine rotavinus in newbom calves fed colostrum supplements from immunized or nonimmunized cows. Infection and Immunity, v.41, p.1118-31, Jan. 1983.

SAS INSTITUTE INC. User's guide. 6, 3. ed. Cary, 1988.

SNODGRASS, D.R.; WELLS, P.W. The Influence of colostrum of neonatal rotaviral infections. Annales de Recherches Veterinaries, v.9, p.335-6, 1978.

TSUNEMITSU, H.; SHIMIZU, M.; HIRAI, T.; YONEMICHI, H.; KUDO, T.; MORI, K.; ONOE, S. Protection against bovine rotavinus in newborn calves by continuous feeding of immune colostrum. Japanese Journal of Veterinary Science, v.51, p.300-8, Fev. 1989.

VENTORP, M.; MICHANEK, P. The importance of udder and teat conformation for teat seeking by the newborn calf. Journol of Dairy Science, v.75, p.262-8, Jan. 1992.

Recebido para publicação em 21.03.95

Aceito para publicação em 22.04.95 